ASTHMA

\title{
Fatty acid levels and risk of asthma in young adults
}

\author{
R K Woods, J M Raven, E H Walters, M J Abramson, F C K Thien
}

Thorax 2004;59:105-110

See end of article for authors' affiliations

Correspondence to:

AssocProfessor FCKThien,

Department of Allergy,

Immunology and

Respiratory Medicine,

Monash University, Central

and Eastern Clinical

School, The Alfred

Hospital, Commercial

Road, Melbourne, Victoria

3004, Australia;

f.thien@alfred.org.au

Received 4 May 2003

Accepted 8 October 2003

\begin{abstract}
Background: There is current interest in the possible protective effect of long chain ( $n-3)$ fatty acids from fish in chronic lung diseases such as asthma. The aim of this community based cross sectional study was to determine whether plasma long chain (n-3) fatty acids, as a measure of dietary intake, differed between 1601 young adults with and without asthma.

Methods: Subjects of mean (SD) age 34.6 (7.1) years completed a detailed respiratory questionnaire, food frequency questionnaire, skin prick testing, and lung function tests including methacholine challenge test for bronchial hyperreactivity (BHR) and had venous blood taken for analysis of plasma fatty acids. Plasma fatty acid levels (\%) were analysed using multiple logistic regression with alternative definitions of asthma and atopy as the outcomes.

Results: Atopy was not associated with any plasma fatty acid. The n-3 polyunsaturated fatty acids and n6:n-3 ratio were not consistently associated with asthma or atopy. The $n-6$ polyunsaturated fatty acid dihomo $\gamma$-linolenic acid (DHGLA) was positively associated with current asthma $(\mathrm{OR}=1.30,95 \% \mathrm{Cl} 1.06$ to 1.60$)$, asthma $(\mathrm{OR}=1.34,95 \% \mathrm{Cl} 1.13$ to 1.60$)$, and doctor diagnosed asthma $(\mathrm{OR}=1.25,95 \% \mathrm{Cl}$ 1.06 to 1.48$)$.

Conclusion: Plasma n-3 fatty acids are not associated with a reduced risk of asthma or atopy among young adults. The association of DHGLA with asthma warrants further research to determine a cause-effect
\end{abstract} relationship.
I nterest in the beneficial health effects of diets rich in marine fatty acids and fish followed observations that some populations with a high dietary intake of fish had a low incidence of inflammatory conditions such as rheumatoid arthritis. ${ }^{1}$ These observations prompted recognition that long chain n-3 fatty acids, principally eicosopentaenoic acid (EPA) and docosahexaenoic acid (DHA) derived mainly from fish, are important components of the human diet. The National Health and Medical Research Council (NHMRC) working party on the role of polyunsaturated fats in the Australian diet has recommended that an increase in the intake of n-3 fatty acids from plant foods and fish be encouraged for its potential health benefits. ${ }^{2}$

Asthma is a major public health problem in Australia and has been declared a national health priority. ${ }^{3}$ One area of current research interest has focused on the possible protective effect of long chain (n-3) fatty acids from fish on chronic inflammatory lung diseases including asthma. ${ }^{4} \mathrm{n}-3$ fatty acids act as precursors leading to the formation of mediators with reduced inflammatory potential. ${ }^{5}$ Previous research has shown that plasma n-3 fatty acid concentrations are related to the dietary intake of long chain n-3 fatty acids, as assessed by 24 hour dietary recall which, in turn, reflects long term intake. ${ }^{6}$ Cross sectional studies in Australia have shown that regular fish consumption, ${ }^{7}$ particularly consumption of oily fish, ${ }^{8}$ may be associated with a reduced risk of asthma in children. However, these studies have assessed the dietary intake of n-3 fatty acids indirectly via dietary questionnaires rather than by direct measurements.

The primary aim of this study was to test the hypothesis that plasma n-3 fatty acid levels, as a measure of dietary intake, are protective against asthma and atopy in young adults. The secondary aim was to determine whether plasma fatty acid levels differed between those with and those without asthma or atopy, in order to generate biological hypotheses regarding specific fatty acids as risk factors for asthma. A range of definitions of asthma was used, from selfreported asthma to epidemiological and physiological defini- tions, since there is no single agreed definition of asthma for research purposes.

\section{METHODS}

The subjects were recruited from a computer generated random sample of 4455 eligible young adults (aged 20-44 years) from the electoral roll in three adjacent electorates in metropolitan Melbourne, Australia. ${ }^{9}$ An initial screening questionnaire was sent to these subjects, of which 3194 $(72 \%)$ responded. The respondents were then invited to attend the laboratory for spirometric testing, methacholine challenge, completion of more detailed questionnaires, and venepuncture for plasma fatty acid analysis.

Participants completed an interviewer administered detailed respiratory questionnaire which has previously been validated and used in the European Community Respiratory Health Survey, ${ }^{10}$ and a validated semiquantitative food frequency questionnaire (FFQ) for assessment of habitual food intake over the preceding 12 months. ${ }^{11}$

Lung function was measured with a rolling seal spirometer (Sensormedics, California, USA). Initial forced expiratory volume in 1 second $\left(\mathrm{FEV}_{1}\right)$ was recorded as the best of five blows which met the American Thoracic Society criteria. Methacholine (Provocholine, Methapharm Inc, Brantford, Ontario, Canada) was delivered by a Mefar 3B dosimeter (Mefar srl, Bovezzi, Italy) up to a cumulative dose of $2 \mathrm{mg}$ $(10 \mu \mathrm{mol})$. Skin prick testing was performed with the following seven airborne and five food standardised allergen extracts: Dermatophagoides pteronyssinus (house dust mite), Lolium perenne (rye grass pollen), ragweed, Cladosporium, Aspergillus, Alternaria, Felis domesticus (cat), cow's milk, egg

Abbreviations: $A A$, arachidonic acid; $B H R$, bronchial hyperreactivity; DHA, docosahexaenoic acid; DHGLA, dihomo $\gamma$-linolenic acid; DPA docosapentaenoic acid; EPA, eicosapentaenoic acid; $F V_{1}$, forced expiratory volume in 1 second; GLA, $\gamma$-linolenic acid; LA, linoleic acid; LNA, $\alpha$-linolenic acid. 
white, wheat, peanut mix, and shrimp (Bayer Corporation, Sydney, Australia), as well as positive (histamine) and negative controls. Wheals were measured after 15 minutes.

\section{Plasma fatty acids (\%)}

Venous blood samples were taken for analysis of plasma fatty acids. Plasma lipids were extracted with chloroform:methanol. ${ }^{12}$ Plasma phospholipids were separated by thin layer chromatography and evaporated to dryness under nitrogen. The samples were methylated and then separated and quantified using a Hewlett-Packard 6890 gas chromatograph. Fatty acid methyl esters were identified according to the retention time to authentic lipid standards obtained from Nucheck Prep Inc (Elysian, MN, USA). Individual fatty acid levels were measured and the results expressed as a percentage of total fat.

The Standing Committee on Ethics in Research on Humans at Monash University and The Alfred Hospital Ethics Committee approved this project. All participants gave written informed consent.

\section{Definitions}

- Atopy: $\geqslant 3 \mathrm{~mm}$ wheal diameter to any allergen.

- Bronchial hyperreactivity (BHR): a provocative dose $\left(\mathrm{PD}_{20}\right)$ of $\leqslant 2 \mathrm{mg}$ inhaled methacholine causing a $20 \%$ fall in $\mathrm{FEV}_{1}$. Bronchial reactivity was also measured as log dose-response (LDR) slope. ${ }^{13}$

- Current asthma: self-reported wheeze in the past 12 months and BHR. ${ }^{14}$

- Asthma: yes to any of "Have you had an attack of asthma in the last 12 months?", "Have you been woken by an attack of shortness of breath at any time in the last 12 months?", or "Are you currently taking any medicine for asthma?". ${ }^{10}$

- Doctor diagnosed asthma: yes to both "Have you ever had asthma?" and "Was this confirmed by a doctor?"

\section{Statistical analysis}

Data were entered, verified, and analyses conducted using the SPSS computer software package (version 10, SPSS Inc, Chicago, IL, USA). Forced entry logistic regression models were constructed to determine whether any plasma fatty acid was an independent predictor of asthma or atopy. The models included the following variables: age, sex, body mass index, smoking status (ever and current), family history of asthma, region of birth, and total energy intake. Separate models were constructed for each individual plasma fatty acid and for each outcome measure. Regression analyses are reported as odds ratios with $95 \%$ confidence intervals for a $1 \%$ change in fatty acid levels. Relationships between fatty acids and markers of asthma severity were assessed using $t$ tests, Mann-Whitney tests, or Spearman rank correlations as appropriate.

We expected that any fatty acid level that had a strong biological association with asthma would be detected across several outcomes in our analysis, but that the size of effect and significance might vary. We were therefore interested in consistent patterns of findings across several outcomes. Because of this, we decided it was reasonable not to perform any further adjustments for multiple comparisons. ${ }^{15}$

\section{RESULTS}

The respiratory questionnaire was completed by 1601 young adults of mean (SD) age 34.6 (7.1) years. Blood samples for fatty acid analysis were obtained for 1090 subjects and the methacholine challenge for BHR was undertaken by 1075 subjects. Forty one subjects (3.8\% of the study population) reported that they were currently taking or had taken fatty

\begin{tabular}{|c|c|}
\hline & $\begin{array}{l}\text { Excluding } 41 \text { fatty } \\
\text { acid supplement } \\
\text { users ( } n=1049 \text { ) }\end{array}$ \\
\hline Mean (SD) age (years) & $35.0(7.33)$ \\
\hline Sex (\% male) & $48.8 \%$ \\
\hline \% Current asthma* & $16.8 \%$ \\
\hline \% Asthma & $24.9 \%$ \\
\hline \% Doctor diagnosed asthma & $26.7 \%$ \\
\hline$\% \mathrm{BHR}^{*}$ & $24.5 \%$ \\
\hline$\%$ Atopic & $63.3 \%$ \\
\hline $\begin{array}{l}\text { Mean (SD) body mass index } \\
\left(\mathrm{kg} / \mathrm{m}^{2}\right)\end{array}$ & $26.0(4.46)$ \\
\hline Mean (SD) \% predicted FEV & $109.31(14.05)$ \\
\hline$\%$ Ever smoked & $43.1 \%$ \\
\hline \% Current smokers & $20.7 \%$ \\
\hline \% Born Australia/New Zealand & $85.1 \%$ \\
\hline Mean (SD) energy intake (Ki) & $9089.60(3644.05)$ \\
\hline Mean (SD) fat intake (g) & $82.75(39.97)$ \\
\hline Mean (SD) protein intake (g) & $97.95(45.09)$ \\
\hline Mean (SD) carbohydrate intake (g) & $230.11(89.40)$ \\
\hline Mean (SD) fibre intake (g) & $23.16(9.15)$ \\
\hline Mean (SD) alcohol intake (g) & $17.52(17.67)$ \\
\hline
\end{tabular}

acid or fish oil supplements in the previous 6 months. Women and those who had ever smoked were both marginally more likely to be taking or have taken fatty acid/fish oil supplements in the previous 6 months $(p=0.02$ and $p=0.03$, respectively). Table 1 summarises the characteristics of the subjects, excluding those on fatty acid supplements $(\mathrm{n}=1049)$

\section{Plasma \% fatty acid levels}

Overall $(n=1090)$ the largest proportions of fatty acids were polyunsaturated (mean $42.9 \%$ ), closely followed by saturated $(41.8 \%)$ and then monounsaturated $(14.1 \%)$ fatty acids. When subjects who were currently or had previously taken fish oil/fatty acid supplements in the previous 6 months $(\mathrm{n}=41)$ were excluded from the analysis, there was no significant change in the mean percentage of plasma saturated, trans, monounsaturated, total n-6 polyunsaturated, or total polyunsaturated fatty acid levels. However, the mean proportion of the n- 6 fatty acids dihomo gamma $(\gamma)$ linolenic acid (DHGLA) and n-6 C22:4 and the n-6:n-3 ratio were significantly lower with this exclusion than when all subjects were included in the analysis. Similarly, the total n-3 fatty acid and the n-3 fatty acids eicosapentaenoic acid (EPA) and docosahexaenoic acid (DHA) were all significantly higher than when all subjects were included in the analysis. For this reason, subjects who reported that they were currently using or had recently used fatty acid or fish oil supplements in the previous 6 months were excluded from all subsequent analyses. The distribution of fatty acids in the remaining 1049 subjects, shown as the mean (SD) concentration of each fatty acid (as a \% of total plasma fatty acids) in both controls and subjects with the various definitions of asthma is given in table 2.

\section{Associations between plasma \% fatty acids and asthma definitions and atopy}

The most consistent associations with definitions of asthma were found with DHGLA and the n-6 fatty acids 20:2 and 22:5 (table 3 ). When the fatty acid/asthma associations were adjusted for the effects of other known and potential confounding factors-that is, age, sex, smoking, body mass index, region of birth, family history of asthma, and total energy intake-consistent associations remained between asthma and DHGLA and the n-6 fatty acid 20:2 (table 4). No 


\begin{tabular}{|c|c|c|c|c|}
\hline \multicolumn{5}{|l|}{$\begin{array}{l}\text { Table } 2 \\
\text { controls }\end{array}$} \\
\hline $\begin{array}{l}\text { Type of fatty acid (no of } \\
\text { cases:controls) }\end{array}$ & & $\begin{array}{l}\text { Current asthma } \\
\text { ( } n=156 / 811)\end{array}$ & $\begin{array}{l}\text { Asthma } \\
(\mathrm{n}=238 / 729)\end{array}$ & $\begin{array}{l}\text { Doctor diagnosed } \\
\text { asthma }(n=257 / 710)\end{array}$ \\
\hline \multicolumn{5}{|l|}{$n-6$ series polyunsaturated } \\
\hline \multirow[t]{2}{*}{ 8:2 LA } & Cases & $20.35(2.85)$ & $20.04(2.83)$ & $20.25(2.89)$ \\
\hline & Controls & $20.15(2.83)$ & $20.23(2.83)$ & $20.16(2.81)$ \\
\hline \multirow{2}{*}{ 8:3 GLA } & Cases & $0.10(0.06)$ & $0.10(0.06)$ & $0.10(0.06)$ \\
\hline & Controls & $0.10(0.06)$ & $0.10(0.06)$ & $0.10(0.06)$ \\
\hline \multirow{2}{*}{$20: 2$} & Cases & $0.35(0.09)$ & $0.35(0.08)$ & $0.35(0.08)$ \\
\hline & Controls & $0.34(0.08)$ & $0.34(0.08)$ & $0.34(0.07)$ \\
\hline \multirow{2}{*}{ 20:3 DHGLA } & Cases & $3.93(0.90)$ & $3.84(0.84)$ & $3.82(0.87)$ \\
\hline & Controls & $3.69(0.85)$ & $3.69(0.86)$ & $3.69(0.85)$ \\
\hline \multirow{2}{*}{$20: 4 \mathrm{AA}$} & Cases & $10.31(2.07)$ & $10.51(1.94)$ & $10.31(2.02)$ \\
\hline & Controls & $10.51(1.82)$ & $10.46(1.83)$ & $10.53(1.80)$ \\
\hline \multirow{2}{*}{$22: 4$} & Cases & $0.35(0.13)$ & $0.35(0.11)$ & $0.35(0.11)$ \\
\hline & Controls & $0.35(0.12)$ & $0.34(0.12)$ & $0.35(0.12)$ \\
\hline \multirow[t]{2}{*}{$22: 5$} & Cases & $0.33(0.16)$ & $0.32(0.14)$ & $0.32(0.15)$ \\
\hline & Controls & $0.31(0.12)$ & $0.31(0.13)$ & $0.31(0.12)$ \\
\hline \multicolumn{5}{|l|}{$n-3$ series polyunsaturated } \\
\hline \multirow{2}{*}{ 18:3 LNA } & Cases & $0.19(0.08)$ & $0.18(0.08)$ & $0.19(0.08)$ \\
\hline & Controls & $0.19(0.08)$ & $0.19(0.08)$ & $0.19(0.08)$ \\
\hline \multirow[t]{2}{*}{ 20:5 EPA } & Cases & $1.16(0.50)$ & $1.16(0.48)$ & $1.16(0.49)$ \\
\hline & Controls & $1.20(0.51)$ & $1.20(0.52)$ & $1.21(0.52)$ \\
\hline \multirow[t]{2}{*}{ 22:5 DPA } & Cases & $1.28(0.42)$ & $1.29(0.40)$ & $1.26(0.39)$ \\
\hline & Controls & $1.28(0.37)$ & $1.28(0.37)$ & $1.29(0.38)$ \\
\hline \multirow[t]{2}{*}{$22: 6 \mathrm{DHA}$} & Cases & $4.28(1.49)$ & $4.39(1.49)$ & $4.33(1.62)$ \\
\hline & Controls & $4.40(1.52)$ & $4.38(1.52)$ & $4.40(1.48)$ \\
\hline \multicolumn{5}{|l|}{ Total } \\
\hline \multirow[t]{2}{*}{$n-6$} & Cases & $35.83(2.55)$ & $35.65(2.48)$ & $35.63(2.55)$ \\
\hline & Controls & $35.58(2.41)$ & $35.61(2.42)$ & $35.62(2.39)$ \\
\hline \multirow{2}{*}{$n-3$} & Cases & $6.96(1.93)$ & $7.07(1.85)$ & $6.99(1.99)$ \\
\hline & Controls & $7.12(1.94)$ & $7.10(1.96)$ & $7.13(1.91)$ \\
\hline \multirow[t]{2}{*}{$n-6: n-3$ ratio } & Cases & $5.53(1.51)$ & $5.40(1.48)$ & $5.49(1.54)$ \\
\hline & Controls & $5.36(1.47)$ & $5.38(1.47)$ & $5.34(1.45)$ \\
\hline \multirow[t]{2}{*}{ Polyunsaturated } & Cases & $43.09(3.15)$ & $42.97(4.10)$ & $42.72(3.94)$ \\
\hline & Controls & $42.85(2.68)$ & $42.80(3.06)$ & $42.89(3.12)$ \\
\hline \multirow[t]{2}{*}{ Saturated } & Cases & $41.88(2.51)$ & $41.89(2.38)$ & $41.95(2.38)$ \\
\hline & Controls & $42.01(2.22)$ & $42.03(2.23)$ & $42.00(2.22)$ \\
\hline \multirow[t]{2}{*}{ Trans } & Cases & $0.66(0.21)$ & $0.66(0.22)$ & $0.68(0.23)$ \\
\hline & Controls & $0.66(0.22)$ & $0.66(0.22)$ & $0.66(0.22)$ \\
\hline \multirow[t]{2}{*}{ Monounsaturated } & Cases & $14.16(1.61)$ & $14.21(1.57)$ & $14.25(1.65)$ \\
\hline & Controls & $14.09(1.53)$ & $14.07(1.53)$ & $14.05(1.50)$ \\
\hline \multicolumn{5}{|c|}{$\begin{array}{l}\text { Data are mean (SD) wt\%. } \\
\text { Note that numbers do not total } 1049 \text { because of missing data. } \\
\text { LA, linoleic acid; GLA, } \gamma \text {-linolenic acid; DHGLA, dihomo } \gamma \text {-linolenic acid; AA, arachidonic acid; LNA, } \alpha \text {-linolenic } \\
\text { acid; EPA, eicosapentaenoic acid; DPA, docosapentaenoic acid; DHA, docosahexaenoic acid. }\end{array}$} \\
\hline
\end{tabular}

consistent associations were found between any of the n-3 series polyunsaturated fats, total polyunsaturated fats, total n-6 fats, total n-3 fats, saturated fats, trans, or monounsaturated fatty acids, or the n-6:n-3 fatty acid ratio and current asthma, asthma, doctor diagnosed asthma, or atopy (table 4). Isolated findings for the n-6 polyunsaturated fat C22:5, n-3 polyunsaturated fat $\mathrm{C} 18: 3$ (LNA), and total saturated fat level did not show consistency across the asthma outcomes (table 4).

\section{Associations between plasma fatty acids and severity of asthma}

The severity markers examined included symptom frequency, bronchial reactivity, and medication requirements. Subjects who reported an asthma attack in the previous 12 months had slightly higher mean levels of the n-6 fatty acid 20:3 $(3.99 \% v 3.70 \%, p=0.004)$, but there were no other significant differences. The number of asthma attacks in the previous 12 months was unrelated to any fatty acid or total fat levels. However, the number of asthma attacks in the previous 3 months was weakly correlated with the n-6 fatty acid 18:2, total n-3 fatty acids, and the n-6:n-3 ratio (table 5). Those who reported frequent nocturnal asthma in the previous 12 months had slightly lower median levels of the n-3 fatty acid $18: 3\left(0.16 \% v 0.18 \%, \chi^{2}=10.7, p=0.03\right)$, but there were no other differences. The frequency of breathing trouble in the previous 3 months was unrelated to the levels of any specific fatty acid or to total levels. Bronchial reactivity ( $\log$ DRS) was weakly correlated with the levels of the $\mathrm{n}-6$ fatty acids 20:2, 20:3, 22:5, the n-6:n-3 ratio, and negatively with the n-3 fatty acid 22:6 (table 5). $\log \mathrm{PD}_{20}$ was only correlated with trans fatty acids $(\rho=0.15, \mathrm{p}=0.03)$. Those who had used inhaled medications in the previous 12 months had slightly higher mean levels of the n-6 fatty acid 20:3 (3.93\% v 3.70\%, $\mathrm{p}=0.001$ ). However, oral respiratory medications in the previous 12 months were unrelated to the levels of any individual fatty acid or to total levels.

\section{DISCUSSION}

This is the first study in which direct measurement of fatty acid levels and possible associations with asthma in young adults have been reported. There was good agreement between the results of the dietary food frequency questionnaire and the plasma fatty acid levels, which has been published elsewhere. ${ }^{16}$ Associations between food and nutrient intake on the questionnaire and the risk of asthma have also been published elsewhere. ${ }^{17}$ The present study did not find any associations between the n-3 fatty acid levels or, indeed, the n-6:n-3 ratio and asthma outcomes or atopy. However, our results indicate that the n-6 polyunsaturated fat DHGLA is most consistently associated with asthma. Various markers of asthma severity were also associated with 
Table 3 Unadjusted odds ratios $(95 \% \mathrm{Cl}$ ) for associations between plasma fatty acids (per 1\% increase) and asthma and/or atopy

\begin{tabular}{|c|c|c|c|c|}
\hline Type of fatty acid & Current asthma $(n=950)$ & Asthma ( $n=1009$ ) & $\begin{array}{l}\text { Doctor diagnosed asthma } \\
\text { ( } n=1007)\end{array}$ & Atopy $(n=1009)$ \\
\hline \multicolumn{5}{|c|}{$n-6$ series polyunsaturated } \\
\hline 18:2 LA & 1.009 (0.95 to 1.07$)$ & $0.96(0.92$ to 1.01$)$ & $1.001(0.95$ to 1.05$)$ & 1.0 (0.96 to 1.04$)$ \\
\hline 18:3 GLA & $2.14(0.12$ to 37.1$)$ & $0.50(0.05$ to 5.51$)$ & $1.45(0.14$ to 14.8$)$ & $17.8(2.00$ to 158$)$ \\
\hline $20: 2$ & $3.98(0.50$ to 31.9$)$ & 6.85 (1.21 to 38.9$)$ & 11.6 (2.14 to 63.3$)$ & $0.26(0.06$ to 1.26$)$ \\
\hline 20:3 DHGLA & 1.44 (1.19 to 1.74$)$ & 1.38 (1.17 to 1.62$)$ & 1.26 (1.08 to 1.48$)$ & $1.06(0.92$ to 1.22$)$ \\
\hline $20: 4 \mathrm{AA}$ & $0.996(0.91$ to 1.09$)$ & $1.07(0.99$ to 1.15$)$ & $0.95(0.89$ to 1.03$)$ & $1.00(0.94$ to 1.07$)$ \\
\hline $22: 4$ & $1.82(0.50$ to 6.64$)$ & $2.09(0.66$ to 6.61$)$ & $1.16(0.36$ to 3.68$)$ & 1.21 (0.48 to 3.07$)$ \\
\hline $22: 5$ & 3.02 (1.02 to 8.96$)$ & $4.31(1.71$ to 10.9$)$ & 2.63 (1.05 to 6.58$)$ & $0.997(0.41$ to 2.42$)$ \\
\hline \multicolumn{5}{|c|}{$n-3$ series polyunsaturated } \\
\hline 18:3 LNA & $1.004(0.12$ to 8.12$)$ & $0.16(0.03$ to 1.01$)$ & $1.24(0.23$ to 7.00$)$ & $0.77(0.17$ to 3.54$)$ \\
\hline 20:5 EPA & $0.93(0.66$ to 1.30$)$ & $0.96(0.73$ to 1.26$)$ & $0.88(0.67$ to 1.15$)$ & 1.001 (0.79 to 1.27$)$ \\
\hline $22: 5$ DPA & $1.26(0.83$ to 1.89$)$ & 1.48 (1.05 to 2.08$)$ & $0.90(0.63$ to 1.27$)$ & $1.36(0.99$ to 1.88$)$ \\
\hline 22:6 DHA & $0.95(0.86$ to 1.06$)$ & $1.04(0.95$ to 1.13$)$ & 0.97 (0.89 to 1.06$)$ & $0.94(0.87$ to 1.01$)$ \\
\hline \multicolumn{5}{|l|}{ Total } \\
\hline$n-6$ & $1.07(0.99$ to 1.14$)$ & $1.04(0.98$ to 1.10$)$ & $1.10(0.95$ to 1.07$)$ & $1.01(0.96$ to 1.05$)$ \\
\hline$n-3$ & $0.97(0.90$ to 1.06$)$ & $1.03(0.96$ to 1.10$)$ & $0.97(0.91$ to 1.04$)$ & $0.97(0.92$ to 1.03$)$ \\
\hline$n-6: n-3$ & 1.07 (0.95 to 1.19$)$ & $0.995(0.90$ to 1.09$)$ & $1.07(0.98$ to 1.18$)$ & 1.05 (0.97 to 1.15$)$ \\
\hline Polyunsaturated & $1.002(0.95$ to 1.05$)$ & 1.02 (0.98 to 1.07$)$ & 0.98 (0.95 to 1.03$)$ & 0.99 (0.95 to 1.03$)$ \\
\hline Saturated & $0.96(0.90$ to 1.03$)$ & $0.92(0.88$ to 0.97$)$ & 0.98 (0.93 to 1.03$)$ & 1.004 (0.96 to 1.06$)$ \\
\hline Trans & $0.91(0.42$ to 1.95$)$ & $0.81(0.43$ to 1.51$)$ & $1.24(0.68$ to 2.27$)$ & $1.23(0.71$ to 2.14$)$ \\
\hline Monounsaturated & $1.02(0.92$ to 1.15$)$ & $1.10(1.005$ to 1.21$)$ & $1.10(1.002$ to 1.20$)$ & $1.04(0.96$ to 1.12$)$ \\
\hline
\end{tabular}

n-6 fatty acids, particularly DHGLA. These results constitute interesting new information and contribute to the understanding of fatty acids and their possible role in asthma and allergic inflammation.

One of the strengths of this study was the ability to examine relationships between dietary fat intake and a number of asthma outcomes. Previous studies have generally relied only on self-reported data or laboratory data. We used self-reported, epidemiological, and physiological definitions of asthma. However, different definitions of asthma do lead to different results, highlighting the importance of careful consideration of the outcome or asthma definition to be used when examining associations between diet and asthma.

Furthermore, previous studies that have found associations between fat intake and asthma have relied on indirect measurements of fat intake, such as food frequency questionnaires or other dietary recall methods. In our study we examined the relationship between fat intake and asthma using a direct marker of fat intake (plasma fatty acid levels). The validity of this approach is confirmed by the fact that fatty acid levels are modified when subjects give a history of nutritional supplementation within the previous 6 months.

We did not find any association between long chain (n-3) fatty acid intake and asthma, as had been suggested by previous studies. A protective association between oily fish intake, assessed by questionnaire, and asthma was reported in a community based survey of Australian school children. ${ }^{8}$ In contrast, a large epidemiological study conducted in the USA (NHANES II) failed to find an independent significant association between fish intake and respiratory symptoms in adults. However, only self-reported outcome measures of wheezing and chronic bronchitis, and not asthma, were used in that analysis. ${ }^{18}$ The difference in the results may be due to the methodological differences between the studies, or could represent a possible contrast between the mechanisms of adult and childhood asthma.

Table 4 Adjusted odds ratios $(95 \% \mathrm{Cl})$ for associations between plasma fatty acids (per 1\% increase) and asthma or atopy

\begin{tabular}{|c|c|c|c|c|}
\hline Type of fatty acid & Current asthma $(n=986)$ & Asthma $(n=1049)$ & $\begin{array}{l}\text { Doctor diagnosed asthma } \\
\text { ( } n=1049)\end{array}$ & Atopy ( $n=1049$ ) \\
\hline \multicolumn{5}{|c|}{$n-6$ series polyunsaturated } \\
\hline 18:2 LA & $0.99(0.93$ to 1.06$)$ & $0.96(0.91$ to 1.01$)$ & 0.98 (0.94 to 1.03 ) & 1.01 (0.96 to 1.06$)$ \\
\hline 18:3 GLA & $1.32(0.07$ to 25.01$)$ & $0.26(0.02$ to 3.24$)$ & $1.44(0.13$ to 16.57$)$ & 7.59 (0.74 to 77.73 \\
\hline $20: 2$ & $2.50(0.24$ to 26.06$)$ & $10.23(1.42$ to 73.46$)$ & $11.10(1.64$ to 75.61$)$ & $1.23(0.20$ to 7.42$)$ \\
\hline 20:3 DHGLA & $1.30(1.06$ to 1.60$)$ & 1.34 (1.13 to 1.60$)$ & 1.25 (1.06 to 1.48$)$ & $1.06(0.91$ to 1.24$)$ \\
\hline $20: 4$ AA & $0.97(0.88$ to 1.06$)$ & 1.05 (0.98 to 1.14$)$ & $0.94(0.87$ to 1.02$)$ & $0.97(0.91$ to 1.04$)$ \\
\hline $22: 4$ & $1.52(0.48$ to 4.78$)$ & 1.07 (0.39 to 2.95$)$ & $1.02(0.38$ to 2.74$)$ & $0.92(0.36$ to 2.36$)$ \\
\hline $22: 5$ & $1.80(0.55$ to 5.88$)$ & 3.64 (1.36 to 9.73$)$ & 1.86 (0.70 to 4.92$)$ & $1.07(0.41$ to 2.79$)$ \\
\hline \multicolumn{5}{|c|}{$n-3$ series polyunsaturated } \\
\hline 18:3 LNA & 0.72 (0.09 to 5.84$)$ & $0.14(0.02$ to 0.86$)$ & 1.05 (0.19 to 5.83$)$ & $1.23(0.24$ to 6.16$)$ \\
\hline 20:5 EPA & $1.01(0.71$ to 1.45$)$ & $1.00(0.75$ to 1.34$)$ & $0.94(0.71$ to 1.26$)$ & $0.98(0.76$ to 1.26$)$ \\
\hline $22: 5$ DPA & $1.13(0.73$ to 1.75$)$ & 1.43 (0.99 to 2.07$)$ & $0.87(0.60$ to 1.26$)$ & $0.97(0.69$ to 1.37$)$ \\
\hline 22:6 DHA & 0.96 (0.86 to 1.07$)$ & $1.05(0.96$ to 1.15$)$ & $0.97(0.89$ to 1.06$)$ & $0.96(0.88$ to 1.04$)$ \\
\hline \multicolumn{5}{|l|}{ Total } \\
\hline$n-6$ & 1.00 (0.94 to 1.07$)$ & 1.01 (0.96 to 1.07$)$ & 0.98 (0.93 to 1.03$)$ & $1.00(0.96$ to 1.05$)$ \\
\hline$n-3$ & $0.98(0.90$ to 1.07$)$ & $1.04(0.97$ to 1.11$)$ & $0.98(0.91$ to 1.05$)$ & $0.97(0.92$ to 1.04$)$ \\
\hline$n-6: n-3$ & $1.03(0.92$ to 1.16$)$ & 0.97 (0.88 to 1.07$)$ & $1.05(0.95$ to 1.15$)$ & $1.06(0.97$ to 1.16$)$ \\
\hline Polyunsaturated & 0.99 (0.94 to 1.05$)$ & $1.03(0.98$ to 1.08$)$ & $0.97(0.93$ to 1.02$)$ & 0.99 (0.95 to 1.03$)$ \\
\hline Saturated & 0.99 (0.92 to 1.06$)$ & 0.92 (0.87 to 0.98$)$ & 1.01 (0.95 to 1.06$)$ & $1.00(0.95$ to 1.06$)$ \\
\hline Trans & $0.64(0.28$ to 1.46$)$ & $0.74(0.38$ to 1.43$)$ & 0.97 (0.52 to 1.83 ) & $1.37(0.76$ to 2.48$)$ \\
\hline Monounsaturated & 0.93 (0.83 to 1.04$)$ & $1.03(0.94$ to 1.13$)$ & 1.03 (0.94 to 1.13 ) & $1.05(0.97$ to 1.15$)$ \\
\hline
\end{tabular}




\begin{tabular}{|c|c|c|}
\hline Type of fatty acid & $\begin{array}{l}\text { No of attacks in previous } \\
3 \text { months }(n=175)\end{array}$ & $\begin{array}{l}\text { Bronchial reactivity logDRS } \\
(n=1013)\end{array}$ \\
\hline \multicolumn{3}{|c|}{$n-6$ series polyunsaturated } \\
\hline $18: 2$ LA & $0.153(p=0.043)$ & 0.055 \\
\hline $18: 3$ GLA & -0.013 & 0.006 \\
\hline $20: 2$ & -0.044 & $0.099(p=0.002)$ \\
\hline 20:3 DHGLA & 0.03 & $0.097(p=0.002)$ \\
\hline $20: 4 \mathrm{AA}$ & -0.032 & -0.034 \\
\hline $22: 4$ & -0.044 & 0.042 \\
\hline $22: 5$ & 0.031 & $0.085(p=0.007)$ \\
\hline \multicolumn{3}{|c|}{$n-3$ series polyunsaturated } \\
\hline 18:3 LNA & -0.106 & 0.033 \\
\hline 20:5 EPA & -0.129 & -0.053 \\
\hline 22:5 DPA & -0.076 & -0.035 \\
\hline 22:6 DHA & -0.098 & $-0.07(p=0.026)$ \\
\hline \multicolumn{3}{|l|}{ Total } \\
\hline$n-6$ & 0.143 & $0.069(p=0.029)$ \\
\hline$n-3$ & $-0.155(p=0.04)$ & $-0.074(p=0.019)$ \\
\hline$n-6: n-3$ & $0.178(p=0.019)$ & $0.081(p=0.01)$ \\
\hline Polyunsaturated & 0.058 & -0.047 \\
\hline Saturated & 0.007 & -0.043 \\
\hline Trans & 0.065 & 0.023 \\
\hline Monounsaturated & -0.079 & 0.045 \\
\hline
\end{tabular}

As with the epidemiological studies, interventional trials of dietary n-3 fatty acid supplementation in asthma have produced some inconsistent results. However, a systematic review of controlled clinical trials of n-3 dietary manipulation in asthma by the Cochrane Collaboration did not find any significant differences in asthma outcomes between low n-3 and high n-3 diets. ${ }^{19}$ The review concluded that there was insufficient evidence to advise on whether dietary manipulation of n-3 fatty acids has any place in the management of asthma. The importance of the current study is that it complements and confirms the overall lack of benefit seen in intervention trials of n-3 fatty acid supplementation for the treatment of established asthma.

Nevertheless, the recent data from childhood epidemiological studies may be interpreted as a possible benefit from n-3 fatty acids in preventing the onset of asthma. Interventional studies to clarify this issue are currently being undertaken, and a positive result may help to reconcile the apparent contradiction between childhood and adult epidemiological data. Similarly, an ecological study in children found an association between trans fatty acids and the prevalence of symptoms of asthma, allergic rhinoconjunctivitis, and atopic eczema. ${ }^{20}$ It is therefore possible that trans fatty acids may have a role in promoting the onset of asthma in children but not in the maintenance of established asthma in adults. Other cross sectional epidemiological surveys have found an increased risk of allergic sensitisation in German children associated with an increased consumption of margarine, ${ }^{21} 22$ but the nature of this association remains uncertain.

It has also been suggested that it is not the absolute amount of $n-3$ or $n-6$ fat intake that is important, but rather the ratio of $n-6: n-3$ fats. Indeed, the ratio of these polyunsaturated fats has been found to be the critical factor affecting eicosanoid formation in rats. ${ }^{23}$ While we found some associations between the n-6:n-3 ratio and more severe asthma, the ratio was not associated with any definition of asthma. Perhaps a greater variation in the n-6:n-3 ratio may be required before a positive anti-asthma effect can be seen in humans.

Our results suggest that it is the n-6 fatty acid DHGLA (C20:3) and C20:2 which are the important dietary risk factors in adults with asthma. The associations with DHGLA were consistent across all of the asthma outcomes, while the associations with n-6 C20:2 were evident in two of the three asthma outcomes that we used. Neither of these fatty acids was associated with atopy. Although the associations for the n-6 fatty acid C20:2 were statistically significant across the asthma outcomes measured, the wide confidence intervals for these associations suggest that larger numbers of subjects are required in future studies to confirm these results. DHGLA is obtained from dietary plant sources and is the immediate precursor for the formation of arachidonic acid through desaturation by the $\Delta 5$ desaturase enzyme. In turn, arachidonic acid is the precursor for a wide range of lipid inflammatory mediators including leukotrienes and prostaglandins. In particular, the cysteinyl leukotrienes are potent inducers of bronchospasm, as well as airway inflammation. Hence, it is biologically plausible that the increased precursor pool is a risk factor for the promotion of asthmatic airway inflammation through generation of proinflammatory mediators. Alternatively, the increased DHGLA may just be an epiphenomenon due to putative decreased $\Delta 5$ desaturase activity in asthma. Whether it is directly causal, an epiphenomenon, or simply a marker for other factors affecting the risk of asthma requires further investigation.

Given the number of comparisons made in this study, some of our statistically significant findings may have been due to chance alone. However, given that the associations between DHGLA were reasonably consistent across all the asthma outcome measures, we are confident that these do represent real underlying patterns of association. We also acknowledge that this was a cross sectional study and therefore our results cannot indicate cause and effect. Furthermore, the association may represent reverse causality if subjects with asthma modified their diets in response to public health messages. It is important that the results are interpreted within this context and that the appropriate longitudinal and intervention studies are conducted to verify our findings.

In conclusion, we have not found any evidence to suggest that n-3 fatty acids are associated with a reduced risk of asthma or atopy among young adults. Indeed, our results suggest that it is the n-6 polyunsaturated fat DHGLA that has the strongest association with asthma. Given that this was a cross sectional study, we were unable to establish a cause and effect relationship for the fatty acids/asthma associations 
found. Nevertheless, these results raise intriguing new possibilities about the role of dietary fats in asthma and warrant further research.

\section{ACKNOWLEDGEMENTS}

The authors thank Mark Neumann, Child Nutrition Research Centre, Flinders Medical Centre, South Australia for performing the fatty acid analyses. Dr Paul Ireland gave permission to use his food frequency questionnaire. They also acknowledge Ms Cathryn Wharton who assisted with data collection and data cleaning, Mrs Judi Wicking, RN who assisted with the data collection phase of the study, and the Cancer Council of Victoria for optical scanning of the food frequency questionnaires.

\section{Authors' affiliations}

R K Woods, M J Abramson, Department of Epidemiology and Preventive Medicine, Central and Eastern Clinical School, Monash University and The Alfred Hospital, Melbourne, Victoria 3004, Australia J M Raven, F C K Thien, Department of Allergy, Immunology and Respiratory Medicine, Central and Eastern Clinical School, Monash University and The Alfred Hospital, Melbourne, Victoria 3004, Australia E H Walters, Discipline of Medicine, School of Medicine, University of Tasmania, Hobart, Tasmania 7000, Australia

This study was funded by the National Health and Medical Research Council of Australia (NHMRC) and the Victorian Health Promotion Foundation (VicHealth). Dr Rosalie Woods held an NHMRC postdoctoral Public Health fellowship (\#987087). None of the study sponsors had any involvement in the study design; collection, analysis and interpretation of data; in the writing of the report; or in the decision to submit the report for publication.

\section{REFERENCES}

1 Cleland LG, French JK, Betts WH, et al. Clinical and biochemical effects of dietary fish oil supplements in rheumatoid arthritis. J Rheumatol 1988;15:1471-5.

2 National Health and Medical Research Council. The role of polyunsaturated fats in the Australian diet. Canberra: Australian Government Publishing Service, 1992.

3 Mathers C, Vos T, Stevenson C. The burden of disease and injury in Australia, Cat no. PHE 17. Canberra: AlHW, 1999.

4 Schwartz J. Role of polyunsaturated fatty acids in lung disease. Am J Clin Nutr 2000;71(Suppl):393-6S
5 Black PN, Sharpe S. Dietary fat and asthma: is there a connection? Eur Respir J 1997; 10:6-12.

6 Bierve KS, Brubakk AM, Fougner KJ, et al. Omega-3 fatty acids: essential fatty acids with important biological effects, and serum phospholipid fatty acids as markers of dietary $\omega 3$-fatty acid intake. Am J Clin Nutr 1993;57(Suppl):801-6S.

7 Peat JK, Salome CM, Woolcock AJ. Factors associated with bronchial hyperresponsiveness in Australian adults and children. Eur Respir $J$ 1992;5:921-9.

8 Hodge L, Salome CM, Peat JK, et al. Consumption of oily fish and childhood asthma risk. Med J Aust 1996;164:137-40.

9 Woods RK, Walters EH, Wharton C, et al. The rising prevalence of asthma in young Melbourne adults is associated with improvement in treatment. Ann Allergy Asthma Immunol 2001;87:117-23.

10 Burney PGJ, Luczynska C, Chinn S, et al. The European Community respiratory health survey. Eur Respir J 1994;7:954-60

11 Ireland P, Jolley D, Giles G, et al. Development of the Melbourne FFQ: a food frequency questionnaire for use in an Australian prospective study involving an ethnically diverse cohort. Asia Pacific J Clin Nutr 1994:3:19-31.

12 Bligh EG, Dyer WJ. A rapid method of total lipid extraction and purification. Can J Biochem Physiol 1959;37:911-7.

13 O'Connor G, Sparrow D, Taylor D, et al. Analysis of dose response curves to methacholine: an approach suitable for population studies. Chest 1987:91:295-6

14 Toelle BG, Peat JK, Salome CM, et al. Towards a definition of asthma for epidemiology. Am Rev Respir Dis 1992;146:633-7.

15 Savitz DA, Olshan AF. Multiple comparisons and related issues in the interpretation of epidemiological data. Am J Epidemiol 1995;142:904-8.

16 Woods RK, Stoney RM, Ireland PD, et al. A valid food frequency questionnaire for measuring dietary fish intake. Asia Pacific J Clin Nutr 2002;11:56-61.

17 Woods RK, Thien F, Raven J, et al. Dietary intake and current asthma risk. Am J Clin Nutr 2003;78:414-21.

18 Schwartz J, Weiss ST. Dietary factors and their relation to respiratory symptoms. The second national health and nutrition survey. Am J Epidemiol 1990;132:67-76.

19 Woods RK, Thien FCK, et al. Dietary marine fatty acids (fish oil) for asthma in adults and children. Cochrane Airways Group. In: Cochrane Database of Systematic Reviews, Issue 3. Oxford: Update Software, 2002.

20 Weiland SK, von Mutius E, Husing A, Asher MI on behalf of the ISAAC steering committee. Intake of trans fatty acids and prevalence of childhood asthma and allergies in Europe. Lancet 1999:353:2040-1.

21 Hirsch T, Kempe G. Consumption of omega-3 and omega- 6 fatty acids in former East and West Germany and changes in East Germany after the reunification. Respir Med 1999;93:213-6.

22 Bolte G, Frye C, Hoelscher B, et al. Margarine consumption and allergy in children. Am J Respir Crit Care Med 2001; 163:277-9.

23 Boudreau MD, Chanmugam PS, Hart SB, et al. Lack of dose response by dietary $n-3$ fatty acids at a constant ratio of $n-3$ to $n-6$ fatty acids in suppressing eicosanoid biosynthesis from arachidonic acid. Am J Clin Nutr 1991;54:111-7. 